Doi: 10.5212/PublicatioCi.Soc.v.21i1.0006

\title{
VIGILÂNCIA COMUNICATIVA? DAS SOCIABILIDADES VIRTUAIS ÀS DEMANDAS RELACIONAIS ENTRE ORGANIZAÇÃO E CONSUMIDOR
}

\author{
COMMUNICATION SURVEILLANCE? FROM THE VIRTUAL \\ SOCIABILITIES TO THE RELATIONS BETWEEN ORGANIZATION \\ AND CONSUMER
}

Wellington Teixeira Lisboa ${ }^{1}$

\begin{abstract}
RESUMO
O presente estudo tem como objetivo central explorar a temática da transversalidade da internet e da virtualidade nas experiências socioculturais dos últimos tempos, destacando pontos de análise que dizem respeito aos desafios epistemológicos e às perspectivas que essa nova realidade sociotécnica imprime à prática profissional e à pesquisa no campo das Ciências da Comunicação, em particular da Comunicação Organizacional. Em um viés interdisciplinar, incide-se sobre um conjunto de posicionamentos teóricos, sistematizados, sobretudo, nos campos da Sociologia e das Ciências da Comunicação, acerca das dimensões estruturais da virtualidade no mundo contemporâneo, sinalizando demandas, riscos e oportunidades na interdependência comunicativa entre organizações e o público consumidor.
\end{abstract}

Palavras-chave: Consumo. Comunicação Organizacional. Sociabilidade.Virtualidade.

\begin{abstract}
The objective of this study is to explore Internet transversality and virtuality in the sociocultural experiences of modernity; the study analyzes in particular the epistemological challenges and prospects that this new reality provides to professional practice and research in Communication Sciences, specifically in Organizational Communication. From an interdisciplinary perspective, the study focuses on a set of theories systematized mainly on Sociology and on Communication Sciences about the structural dimensions of virtuality in the contemporary world, signaling demands, risks and opportunities in the communicative interdependence between organizations and consumers.
\end{abstract}

Keywords: Consumption. Organizational Communication. Sociability.Virtuality.

${ }^{1}$ Doutorando em Sociologia na Universidade Estadual de Campinas (Unicamp). Mestre em Ciências da Comunicação pela Universidade de Coimbra. Docente e pesquisador no Centro de Ciências Exatas, Artes e Humanidades da Universidade Católica de Santos. E-mail: wtlisboa@yahoo.com.br 


\section{Introdução}

$\mathrm{O}$ acesso à multiplicidade de informações por meio da rede mundial de computadores, a internet, bem como a emergência de interações sociais estruturadas no âmbito da esfera virtual, constituem-se um fenômeno que vem se consolidando nas últimas três décadas. Particularmente nas áreas das Ciências Humanas e Sociais, muitas são as interrogações suscitadas no tocante à ligeira incorporação dos aparatos tecnológicos informativo-comunicacionais nas dinâmicas da vida cotidiana de indivíduos e grupos, projetando uma arena de debates multifacetada, que põe em xeque questões de importância para o exercício de compreensão das sociedades contemporâneas.

O presente estudo tem como objetivo central explorar um conjunto de argumentações teóricas que incidem, especificamente, sobre a temática da transversalidade da internet e das práticas virtuais nas experiências socioculturais dos últimos tempos, a exemplo das experiências individuais e coletivas de consumo e do redimensionamento dos vínculos entre organizações e seus públicos de interação, como, por exemplo, o consumidor.

Nesse sentido, debruçar-nos-emos, primeiramente, sobre posicionamentos reflexivos esboçados por autores que vêm se especializando na temática da virtualidade, a exemplo de Lúcia Santaella, Manuel Castells, Pierre Lévy, Maximodi Felice, Alex Primo e outros. Priorizam-se, numa perspectiva dialógica e com viés sociológico, as abordagens analíticas que remetem ao papel da internet como suporte técnico e simbólico que possibilita distintas formas de sociabilidade, com implicações múltiplas no âmbito privado e, em especial, na esfera pública.

De um modo geral, interessa-nos compreender as ações e interações do ser humano nesse novo ambiente multifuncional que, em ritmo veloz e constante, propõe outras configurações aos exercícios representacionais da imaginação (MACHADO, 1996; APPADURAI, 2004) e às memórias individuais e coletivas (LEMOS, 2002; COSTA, 2003), também sinalizando dimensões inovadoras da comunicação institucional, bem como vias de conhecimento amplificadas na vida do homem do século 21 .

Esse arcabouço de reflexões permitirá, num segundo momento, que apresentemos alguns pontos de análise a respeito dos desafios epistemológicos e das perspectivas que essa nova realidade sociotécnica (LÉVY, 2001) imprime, tanto à prática profissional quanto à pesquisa no campo das Ciências da Comunicação, em particular da Comunicação Organizacional, aqui enfatizada, sobretudo, na dimensão do consumo.

Entretanto, considerando a complexidade e as múltiplas nuances a serem observadas no tocante às transformações em curso na vida social e, como corolário, neste campo científico, torna-se evidente que nossas ponderações caracterizem-se, em molde ensaístico, pelo enfoque nos aspectos gerais da problemática ora referendada.

Tal problemática, a saber, concerne à emergência de sociabilidades mediadas por dispositivos virtuais informativo-comunicacionais e às demandas e competências que, tendo em vista o contexto histórico, já vêm sendo requeridas aos profissionais e estudiosos da Comunicação Social.

\section{Da construção do mundo global: economia, tecnologias e hibridismos imaginários}

À partida, importa-nos sublinhar que a origem do desenvolvimento da rede de computadores e da internet remonta à década de 60 do século XX, quando a telefonia constituía a rede de comunicação mundialmente dominante. $\mathrm{O}$ aperfeiçoamento de computadores com multiprogramação e a importância cada vez maior de dados computadorizados no início daquela década impulsionou, ainda que a um custo elevado, as tentativas de interligar computadores que possibilitassem aos usuários, situados em distintas localizações geográficas, partilhar as mesmas informações.

Como salientam James F. Kurose e Keith W. Ross (2010), referências norte-americanas nas áreas de Informática e Engenharia da Computação, é bem provável que o tráfego de informações gerado pelos usuários se estruturasse em forma de rajadas, isto é, períodos de atividade sequenciados por períodos de inatividade, esses últimos identificados como o tempo necessário à tramitação de resposta ou à certificação de mensagem recebida. Estes autores também mencionam que, naquela década, três grupos de pesquisa, sem o conhecimento de que trabalhos similares estavam sendo realizados em outras partes do mundo, começaram a desenvolver experimentos no 
campo das Ciências da Computação. Os interesses que estimulavam tais iniciativas científicas diziam respeito, sintomaticamente, à urgência de descentralização geográfica da informação no contexto da Guerra Fria, o que potencializava ações conjuntas e mais efetivas entre os países envolvidos no bloco capitalista.

No Massachusetts Institute of Technology e no Rand Corporation, ambos nos Estados Unidos, e no National Physical Laboratory, localizado na Inglaterra, configurava-se o alicerce para o que, pouco tempo depois, funcionaria no mundo com a denominação de internet. Kurose e Ross (2010) explicam que esse pontapé instigou pesquisadores norte-americanos, vinculados à Advanced Research Projects Agency (ARPA), ao aperfeiçoamento e à publicação de planos para a ARPAnet, a primeira rede de computadores e uma ancestral direta da internet pública de hoje. A ARPAnet seguiu desenvolvendo seu sistema, mas, em meados da década de 70, surgiram outras redes, como a ALOHAnet, que interligava as universidades das ilhas do Havaí via frequência de rádio; a Telenet, uma rede da $\mathrm{BBN}$ Technologies baseada na tecnologia da ARPAnet; além de redes francesas. No início dos anos 80, os franceses lançaram o projeto Minitel, expandindo a rede para todos os lares da França, cuja população passou a ter acesso a sites livres e também particulares, com base no pagamento de uma taxa calculada proporcionalmente ao tempo de uso. Ao final daquela década, o número de máquinas ligadas à internet pública alcançava cerca de cem mil, sendo que os esforços para a criação de redes de computadores visavam, sobretudo, à interligação no campo da ciência, em especial entre institutos de pesquisa e universidades dos Estados Unidos (KUROSE; ROSS, 2010).

Como contextualiza Levine (1998), na década de 90 do último século, começa a funcionar a word wide web, que propiciou a expansão da internet nos lares e instituições em todo o mundo, operando com cada vez mais serviços informativos e comunicacionais, como banco de dados, operações bancárias, armazenamento e recuperação de informações, canais de comunicação interpessoal e grupal, correio eletrônico, atividades sofisticadas de multimídia e entretenimento e, inclusive, a proliferação de dispositivos facilitadores do comércio eletrônico, tornando a internet um componente central das telecomunicações e da movimentação da economia em escala global. Este autor também assinala que, em ritmo acelerado, desde meados dos anos 1990, o aperfeiçoamento da multifuncionalidade da internet vem sendo orientado segundo necessidades e demandas das mais diversas ordens, dinâmica que posiciona essa plataforma de atividades não meramente técnicas, mas, manifestamente, sociais, políticas, econômicas e culturais (MOSCO, 2004; TRIVINHO, 2007; DI FELICE, 2008), como uma sólida infraestrutura computacional na qual as possibilidades de atuação humana tendem à rápida ampliação, não obstante as limitações sócio-históricas contingenciais e as emergentes fronteiras éticas e filosóficas (TRIVINHO, 2007; DI FELICE, 2008).

Lúcia Santaella (2000) pontua que, atualmente, a internet apresenta-se como uma espécie de simbiose entre os meios de difusão de informação e os meios técnicos de interação social. Permite, por um lado, que uma mesma informação seja dirigida a números incalculáveis de pessoas e, por outro, que cada um dos sujeitos da audiência interaja com a informação enviada, com a sua fonte e com os demais destinatários do mesmo discurso, numa lógica de "todos para todos". Nesse sentido, na acepção desta autora, pode-se depreender que o contínuo e direto envolvimento entre homem e máquina. $\mathrm{O}$ processo histórico de criação e desenvolvimento de meios tecnológicos de comunicação proporciona a extensão e ressignificação das possibilidades de ação humana, nos últimos anos mediada por ondas de rádio, fibras óticas, satélites, plasmas, LCDs digitais, telefonia celular, computadores da mais moderna tecnologia.

Certas mudanças socioculturais estimuladas (e não propriamente gestadas) pelos aparatos tecnológicos de informação e comunicação, dos mais "tradicionais" àqueles que, com inovadores dispositivos e formatos, são introduzidos nas práticas cotidianas de indivíduos de distintas gerações, classes, etnias, nacionalidades, revelam-nos que supostas tendências e verdades tidas como perenes, sobretudo no que toca à interação do homem no mundo que lhe é envolvente, sofrem um paulatino movimento de reconfiguração, desconstrução, ou mesmo, implosão.

$\mathrm{Na}$ obra intitulada Cultura e artes do pós-humano: da cultura das mídias à cibercultura, Santaella (2003) chama a atenção à evolução protagonizada pelas mídias nos últimos tempos e, em 
sentido análogo, às movimentações socioculturais que ocorreram desde as primeiras décadas do século $\mathrm{XX}$, com o advento do cinema e rádio, até a experiência do homem deste século XXI, em larga medida transversalizada por suportes de comunicação que dão vazão a uma cultura pautada em convergências tecnológicas² (JENKINS, 2008).

$\mathrm{Na}$ passagem, atualmente em curso, de uma alegada "revolução eletrônica" para a "revolução digital” (VILCHES, 2003), com suas máquinas-dispositivos interligadas às telecomunicações em dimensão planetária, a exponenciação da complexidade do campo da comunicação humana atinge escala sem precedentes.

De forma ampla, os computadores e programas avançados de informática passaram a ser fundamentais nos ambientes domésticos e de trabalho, bem como em distintas esferas da produção de conhecimento, das práticas de consumo e lazer, dos relacionamentos de governos e empresas com os cidadãos, da mobilização em prol da democracia, da elaboração imaginária de identidades pessoais e projetos de vida (APPADURAI, 2004), cumprindo uma função essencial na comunicação cotidiana e na troca de informações de naturezas diversas. O que mais impressiona, na interpretação de Santaella (2003), não é tanto a novidade do fenômeno que se interpôs, sobretudo, no limiar do presente século, mas o ritmo acelerado das inovações tecnológicas e os consequentes impactos econômicos, científicos, psíquicos e culturais, provocados de forma generalizada.

Posicionando-se nessa vertente de entendimento, Manuel Castells (2007) também concebe os dispositivos tecnológicos como fenômeno basilar à emergência e funcionamento da sociedade contemporânea, por este autor denominada como "informacional", "sociedade em rede", destacando que

\footnotetext{
${ }^{2}$ Convergência tecnológica e midiática, ou migração digital, são expressões que vêm sendo utilizadas no sentido de definir as transformações tecnológicas, mercadológicas e socioculturais processadas no cenário contemporâneo dos meios de comunicação. Referem-se, em particular, ao fluxo de conteúdo que perpassa múltiplos suportes e mercados midiáticos, considerando o comportamento migratório percebido no público, que oscila entre diversos canais (televisão, rádio, celulares, jogos, internet) em busca de novas experiências de entretenimento e comunicação. Na concepção de Jenkins (2008), o conceito de convergência diz respeito ao paradigma configurado para representar a mente dos consumidores, identificando suas interações sociais plasmadas nas formas de consumo e nas relações dos usuários com as tecnologias contemporâneas. A convergência midiática, neste sentido, resvala, sobretudo, nos processos socioculturais e não se reduz tão somente a mutações tecnológicas.
}

o arcabouço tecnológico centrado na informação e comunicação, em especial a internet, veio estruturar um suporte indispensável para que as economias por todo o mundo passassem a manter o atual estágio de interdependência, gerando implicações múltiplas nos âmbitos políticos e socioculturais. A inserção das tecnologias de informação e comunicação em inúmeras esferas da atividade humana afigura-se, como sublinha Castells (2007), como um dos pontos nodais sobre o qual se requer incidir no sentido de apreender a complexidade que permeia e define as economias, as sociedades e as culturas em ligeiro processo de redesenho no espaço-mundo.

É precisamente nesse sentido que este sociólogo espanhol posiciona a relevância dos sistemas de telecomunicações e da internet num patamar equivalente ao advento da eletricidade que, a princípio na Inglaterra, consolidou o processo de industrialização nos séculos XVIII e XIX, com base no qual os campos e as cidades, os transportes, as fábricas, as rotinas produtivas, as formas de comunicação e os hábitos e estilos de vida passaram por profunda recomposição (CASTELLS, 2002; HOBSBAWM, 2009a, 2009b). No entendimento de Castells (2002, 2007), os sistemas de comunicação fundados na internet representam o atual epicentro a partir do qual se formula e irradia um universo complexo de atividades que, de maneiras múltiplas, desiguais, hierarquizadas, ganham concretude nos territórios centrais e intersticiais da "sociedade em rede". Esse epicentro desponta como força-motriz estruturante na construção cotidiana de significados socialmente válidos. As redes interativas de informação e comunicação digital tornaram-se, assim, tanto componentes articuladores da estrutura social local quanto agentes mobilizadores de transformações sociais globais, sendo pertinente, na concepção de Castells (2007), atribuir a denominação "sociedade em rede" à nova configuração socioeconômica vigente.

A internet penetra em todos os domínios da vida social e os transforma. Assim é uma nova configuração, a sociedade em rede, que está em gestação em todo o planeta, ainda que sob formas muito diversas entre um ponto e outro e com efeitos muito diferentes sobre a vida das populações, devido à sua história, sua cultura, suas instituições. Como as mutações estruturais anteriores, essa reviravolta traz consigo tantas possibilidades quanto proble- 
mas novos. O resultado que daí surgirá é indeterminado: dependerá de uma dinâmica contraditória, da eterna luta entre os esforços sempre renovados para dominar, para explorar, e a defesa do direito de viver e de procurar dar um sentido à própria vida. (CASTELLS, 2002, p. 333).

Nessa perspectiva, revelar-se-ia infrutífero o exercício de compreensão (caracteristicamente tangencial) das sociedades contemporâneas sem uma análise da transversalidade e potencialidade da internet em diferenciados domínios da ação humana, seja no campo político, econômico, educacional, nas novas formas de mobilização coletiva e participação democrática, seja nas configurações globais de trabalho, no lazer e consumo, cultura e entretenimento, nas artes, nas mutações de subjetividade e intimidade. Anthony Giddens $(1995,2002)$ defende que o estudo da constituição das sociedades modernas, na complexidade tal como se apresenta, torna-se infundado sem se levar em conta as consequências que a globalização, largamente alicerçada em suportes tecnológicos de informação e comunicação, o que a autoriza a romper com noções tradicionais, fixas, de espaço, tempo e suas correlações, imprime tanto ao indivíduo quanto à coletividade, contribuindo, de forma decisiva, para afetar "os aspectos mais pessoais de nossa existência". (GIDDENS, 2002, p. 9).

Este sociólogo inglês chega a destacar as transformações que vêm se desvendando, inclusive, no universo privado da intimidade e da sexualidade, abarcando até mesmo as representações sociais do amor, do prazer e do erotismo, o que nos permite inferir que, para além de certos fatores histórico-culturais que legitimam os comportamentos individuais na contemporaneidade, as ações de homens e mulheres nos seus cotidianos dispõem, há poucos anos, de novas formas de interação e de busca e uso de informações. Complexa, transversal, labiríntica, a realidade virtual propicia a sempre inacabada reconstrução de volúveis, por vezes irreconhecíveis, identidades pessoais. A internet e a virtualidade, como prática decorrente de suas formas constitutivas, traduzem, pois, a face (in)visível dos novos dispositivos de transmissão da informação e da comunicação global, sendo que seus impactos imediatos generalizam-se, de modo espontâneo e superabundante, em âmbitos diversificados da vida social e da cultura.

\section{Transversalidades: do privado ao público e vice-versa, o virtual como realidade}

O conceito virtual está associado a uma categoria composta pelas noções de processo e estado: a primeira, pelo fato de representar uma configuração operacional aberta e em permanente e ágil transformação; a segunda, por exigir conexão a uma malha de computadores globalmente estruturada (HEIM, 1998). Sob esses aspectos, o virtual implica uma ligação direta a um universo de linguagens, códigos, protocolos, informações e práticas que transbordam os limites de uma pretensa "realidade física", penetrando em outro território simbólico ${ }^{3}$ em relação ao qual vem se convencionando a denominação de espaço virtual ou, mais especificamente, ciberespaço.

O termo cyberespace apareceu pela primeira vez no livro Neuromancer, de autoria de William Gibson, referindo-se a todo o espaço, intangível e atemporal, que é criado pelas comunicações mediadas por computador.

Nesta obra publicada em 1984, que agrega inquietações de cunho histórico, sociológico e filosófico a tramas ordenadas por enredos caracteristicamente de ficção científica, o ambiente virtual proporcionado pelas redes de computador conduz o desenrolar das narrativas que se cruzam em torno do protagonista anti-herói, um ex-hacker que foi forçado a se aposentar prematuramente porque, após uma bem-sucedida tentativa de roubar seus empregadores, recebe como castigo a trituração de seus implantes neurais, os mesmos que lhe dão acesso ao cyberespace ${ }^{4}$.

Como declara Fernandes (2006) em seu livro sobre as inter-relações entre a construção temporal de um "imaginário cyber" e imagens, ideias e fantasias originalmente trabalhadas por William Gibson, a vida no submundo das operações obscuras de transferência de dados e da genética ilegal compõe a temática central dessa que foi uma das mais

\footnotetext{
${ }^{3} \mathrm{~A}$ noção de territorialidade já não se encontra apenas associada à materialidade do entorno físico. O cinema, a televisão, o telefone e a internet aproximam as pessoas, podendo-se "falar da existência de relações sociais planetarizadas, isto é, de um modo real e imaginário que se estende, de forma diferenciada é claro, por todo o planeta" (ORTIZ, 2002, p. 273).

${ }^{4}$ Este livro serviu de inspiração para a trilogia cinematográfica intitulada Matrix, dos irmãos Andy e Larry Wachowski. Interessante também registrar que William Gibson trabalhou nos roteiros dos filmes Alien3 (1992), Johnny Mnemonic (1995) e New Rose Hotel (1998), todos sobre ação e ficção científica, além de episódios do seriado Arquivo X.
} 
importantes obras de ficção científica de fins do século XX.

A notoriedade expressa em Neuromancer, na acepção de Fernandes (2006), reside não apenas no fato de, àquela época, propagar uma visão premonitória de um futuro próximo e possível, em especial no que diz respeito ao aparecimento da internet e à ênfase que se atribui às práticas virtuais nos cotidianos individuais e coletivos, mas, sobretudo, pela influência que teve na criação e rápida adesão de um novo vocabulário, ou melhor, um léxico até então desconhecido, no qual se sobressaem conceitos como ciberespaço e realidade virtual.

Pierre Lévy (2001), um dos autores que se apropria dessas terminologias no intuito de compreender a emergência da virtualidade nas experiências socioculturais das últimas décadas, salienta que o assim chamado ciberespaço é mais do que a infraestrutura da comunicação digital interativa que tem como locus a rede telemática, pois envolve também todos os elementos heterogêneos que intervêm nos processos comunicativos desenvolvidos nesse espaço antropológico. O ciberespaço, nessa perspectiva, pode ser dimensionado como um amplo e complexo sistema tecnológico ramificado que opera com trocas simbólicas e processos de significação social na esfera virtual. Assim, caracteriza-se como um território abstrato que suporta uma infindável gama de dados, textos, aplicativos, recursos e informações, bem como um mosaico de realidades sociais e culturais afins ou totalmente diversas, que são alimentadas na rede por interlocutores, predominantemente jovens, situados nos mais variados pontos geográficos do planeta.

Não se pode desmerecer o fato de que a dinâmica material e imaterial do que se convenciona denominar como ciberespaço é fomentada pelo avanço das forças produtivas do sistema capitalista, no seu empenho incessante em ampliar a velocidade de rotação do capital e das transações financeiras em escala planetária (HARVEY, 1992).

Na acepção de Giovanni Alves (2012, p. 70), pensador marxista especializado na temática das configurações das relações de trabalho na atualidade, "o sistema mundial do capital em sua etapa mais desenvolvida possui, como pressuposto material, uma base técnica complexa de matriz informacional, caracterizada por redes informáticas e telemáticas de comunicação". O autor lembra que foram as empresas de capital concentrado e os grupos industriais dos setores manufatureiro e de serviços os pioneiros na adoção das novas tecnologias de informação e comunicação, impulsionando o redesenho do contexto histórico da hegemonia neoliberal vigente e contribuindo para com o processo de mundialização do capital e de suas forças, implacavelmente vorazes, imperativas, excludentes. É nesta linha de reflexão que, complementarmente, Francisco Rüdiger (2011, p. 68) conclui que

[...] os computadores e celulares, por exemplo, podem ser postos a serviço do mercado tanto quanto da educação; da competição tanto quanto da solidariedade. As alternativas não são fantasias utópicas, mas possibilidades reais contidas em nossa sociedade, ainda que de maneira latente, devido ao predomínio das relações sociais criadas, mantidas e reproduzidas pelo sistema dominante: o capitalismo.

Logo, a internet potencializa a emergência de um espaço de interação e negociação global muito mais abrangente e complexo do que pode sugerir a ideia de um megacircuito de computadores interligados em série ${ }^{5}$. Como sustenta Lévy (2000), o ciberespaço envolve uma rede mundial de informações digitais armazenadas ou em constante movimento, a serviço de governos, organizações não governamentais, microempresas ou megacorporações, como comporta uma imensa teia de pessoas interconectadas ao mesmo instante, com fins diversos. Essas são razões pelas quais este autor salienta que a internet propicia a inédita experiência de uma inteligência coletiva partilhada entre os homens (LÉVY, 2003). As inteligências individuais, nessa linha de entendimento, são somadas e dadas a conhecer por toda a sociedade globalizada, e as novas tecnologias de

\footnotetext{
${ }^{5}$ Lévy (2000) chega a usar o neologismo cibercultura para definir esse conjunto de técnicas (materiais e intelectuais), atitudes, linguagens, práticas, referentes simbólicos, modos de pensamento e valores que se desenvolvem simultaneamente ao alargamento contínuo do ciberespaço. A emergência da cibercultura provoca, na concepção deste autor, uma mudança radical na memória e no imaginário humano, transformando a natureza das relações dos homens com a tecnologia e entre si. A cibercultura nomearia, pois, a cultura contemporânea fortemente mediada e reinventada com apoio das tecnologias digitais. Não exploraremos, neste estudo, as explicações e implicações teóricas que envolvem o que muitos autores, a exemplo de Pierre Lévy, vêm denominando como cibercultura, precisamente por concebermos que esta terminologia pode representar um esforço não consistente de categorizar um campo demasiado complexo, o da cultura, que não pode ser reduzido a tais definições homogeneizantes.
} 
informação e comunicação, em especial a internet, possibilitam esse universo comum de memórias, imaginários, percepções e (re)conhecimentos.

Os usuários da rede aberta da internet, situados nos mais diversos pontos do planeta, têm a possibilidade de se apropriar de informações e serviços em escala mundial e de maneira instantânea, como jamais se registrou na história do envolvimento entre homem e máquina. Não obstante, acompanha-se a proliferação de formas de contato, comunicação e manutenção de sociabilidades, novas e/ou já existentes, por meio de troca de mensagens no espaço virtual, via texto, som, voz, imagem, vídeo, ou mesmo por meio do hibridismo de diferentes canais, em formato de hipertexto (SANTAELLA, 2004).

As comunidades virtuais, como aquelas que se formam em salas de chat, blogs, fotologs, facebooks, orkuts, linkedln, msn, emergem como exemplos paradigmáticos de redes de interação que se desenvolvem e se pulverizam na plataforma informativo-comunicacional da internet.

No caso do facebook, ferramenta por meio da qual, mais explicitamente, é possível cartografar as sociabilidades que são operadas em ambiente virtual, pode-se identificar uma cadeia de conexões diretas e indiretas, bem como diversas organizações sociais que se manifestam na rede em forma de comunidade. Essas ferramentas também possibilitam outros tipos de interação e representação coletiva, à primeira vista, desprovidas de marcações espaço-temporais, tais como sistemas de fóruns de discussões, envio de mensagens para amigos, para amigos de amigos e para outras comunidades cujo endereço define-se como um locus abstrato no mundo virtual. Como analisa Recuero (2009), tradicionalmente, comunidade, para os cientistas sociais, tem sido um conceito associado a um grupo de pessoas que divide proximidade, intimidade, confiança e outros tipos de capital social, tal como propôs o sociólogo alemão Ferdinand Tönnies ${ }^{6}$, em 1887, ou, mais recentemente

\footnotetext{
${ }^{6} \mathrm{Na}$ sua célebre obra intitulada Gemeinschaft und Gesellschaft, que em português significa Comunicação e Sociedade, Tönnies (1973) defende a comunidade como um tipo especial de associação, plasmada na noção de territorialidade, cujos laços naturais respeitam os imperativos do próprio ser, ou seja, engloba a comunidade de sangue, como a família, a comunidade de vizinhança, como as que se formam nas aldeias e pequenas cidades pré-industriais, além das comunidades formadas por afinidades religiosas ou agremiações nas cidades. Na sociedade, em contrapartida, as pessoas permanecem essencialmente separadas, não obstante os agentes que estimulam sua unificação. O Estado, o sistema capitalista e a complexa
}

e sob sua ótica particular, chamou a atenção o sociólogo polonês Zygmunt Bauman ${ }^{7}$ (2003).

De forma quase idealizada, a comunidade aparece no discurso das Ciências Sociais, em âmbito teórico e metodológico, como um grupo de pessoas que partilha relações cotidianas próximas e afetivas, face a face, numa circunscrição geográfica definida. No entanto, nos sites de rede social, a noção de comunidade está diretamente ligada à associação de pessoas em torno de uma ideia ou valor, sem a necessidade de referentes geográficos que as aproximem. Sendo assim, como descreve Recuero (2009), as comunidades virtuais são constituídas pela proximidade intelectual e emocional de seus membros, independentemente de que locais do planeta habitem os internautas. Os participantes reconhecem-se como parte de um grupo e como responsáveis pela manutenção de suas sociabilidades, que podem ganhar corpo e se reproduzir em ocasiões que demandam dos sujeitos estarem fora do ambiente virtual, se porventura houver contiguidade espacial.

Por sua vez, Rheingold (2000) explica que essas comunidades são agregações sociais que se configuram na rede telemática quando um número suficiente de pessoas, com interesses, estórias, ligações, repertórios culturais comuns, comunica-se no intuito de formar ou manter teias de relações pessoais para além de uma pretensa "realidade física", ou como seu complemento. São grupos que se constituem, se expressam e se fortalecem tendo como ponto de referência o endereço identificado na plataforma virtual. Por um sistema de teleconferência por computador, por exemplo, é possível que pessoas de todo o mundo participem de conversas coletivas e troquem correspondências por meio de correio eletrônico, seja no sentido de partilhar percepções em torno de uma causa pública de interesse social, seja para apreciar

\footnotetext{
divisão do trabalho, a opinião pública, na concepção de Tönnies, são expressões fundamentais da vida humana em sociedade, em que as relações, ao contrário do que se processa na comunidade, se caracterizam pela impessoalidade, individualidade e por sociabilidades mercantilizadas.

${ }^{7}$ É interessante a análise de Bauman (2003) sobre a tradicional ideia de comunidade, fundamentada na noção de segurança, liberdade, territorialidade, coletividade, conforto e proteção. Em linhas gerais, na sua concepção, as condições para a existência de comunidades já não se aplicam na contemporaneidade, caracterizada pela "modernidade líquida" e suas inconstantes configurações. Os atuais aspectos estruturais relacionados ao tempo, espaço, tecnologias, transporte, individualidade, política, economia implodiram o antigo significado de comunidade. A exemplo, este autor sublinha que o individualismo emergiu como a "marca registrada" da modernidade.
} 
artefatos de consumo, seguir tendências da moda, cultuar ou se opor a celebridades, empresas, seus serviços, marcas e propagandas, comentar e sugerir notícias nacionais e internacionais, adquirir, divulgar ou criticar meios de entretenimento e produtos ofertados no cíclico movimento do mercado e das indústrias culturais. Inegavelmente, são múltiplas as motivações e os interesses que movem agrupamentos humanos a interagir, em dimensão transfronteiriça, na instantaneidade e fluidez proporcionadas pelos suportes digitais de comunicação.

Frente à emergência desse cenário característico do presente século, que se desenha e se reconfigura a uma velocidade fulgurante que dificulta o exercício de interpretação de seus contornos transitoriamente constitutivos, autores como André Lemos, Máximo di Felice, Engênio Trivinho, Lúcia Santaella, Manuel Castells, Pierre Lévy e outros são consensuais quanto ao reconhecimento da complexidade dos laços humanos emaranhados no ambiente virtual, pontuando que o ciberespaço não se define somente como uma entidade cibernética funcional que potencializa, em particular, negociações financeiras em escala global. As transações operadas na esfera virtual, tanto aquelas que atendem explicitamente a demandas capitalistas quanto as que se desenvolvem como práticas de sociabilidade desprovidas, à primeira vista, de caráter mercadológico, despontam como elementos fulcrais da cultura contemporânea e desempenham um importante papel de complexificador e estruturador do real. Daí o crescente interesse por parte das Ciências Humanas e Sociais em compreender a operacionalidade e os diferentes sentidos e dilemas que se edificam na utilização sistemática desse novo locus, o ciberspaço, que se instala como plataforma estrutural da contemporaneidade.

\section{Vigilância comunicativa: estratégias e riscos na interdependência organização/ consumidor}

As distintas sociabilidades levadas a cabo em ambiente virtual e, frequentemente, prolongadas nas interações cotidianas de indivíduos e grupos, colocam novos desafios à prática e à pesquisa no campo das Ciências da Comunicação, particularmente à Comunicação Organizacional, foco deste estudo. Já não se qualifica como novidade, nesta segunda década do segundo milênio, o fato de as mídias sociais, por exemplo, alçarem um papel de destaque na comunicação empreendida pelas organizações públicas e privadas, independentemente do setor de atuação e de seu porte, com os cidadãos, consumidores e com os distintos agrupamentos humanos que manifestam algum tipo de necessidade ou interesse em relação à organização, constituindo-se como um de seus públicos de relacionamento. A emergência desse cenário, forjado por relações mediadas por dispositivos virtuais de comunicação, demanda às áreas da Publicidade e Propaganda e das Relações Públicas, para além do campo do Marketing, a elaboração de novos estudos e inovadoras propostas de comunicação que deem conta das singularidades e, em especial, das oportunidades ofertadas pelos ambientes tecnológicos de interatividade.

Stasiak (2010), em perspectiva análoga às ponderações de José Benedito Pinho (2003) e Margarida Kunsch (2003), sublinha que planejar, executar e avaliar ações de comunicação institucional tornaram-se, nos últimos anos, atividades mais complexas e desafiadoras, por conta das novas formas de relacionamento proporcionadas pelas tecnologias digitais, que permitem a interação direta, noutra dimensão temporal, entre uma organização e seus públicos, e vice-versa. Como descreve a autora, até pouco tempo, para alcançar notoriedade pública, era necessário que as informações institucionais se submetessem ao filtro das mídias tradicionais consideradas massivas, como televisão, rádio, jornal impresso, etc. Com o advento e o movimento acelerado de expansão da internet, o empenho por visibilidade e, mais do que isso, por legitimidade social, requer das instituições a gestão estratégica de políticas de relacionamento que, para além da publicidade na "grande mídia", contemplem o mosaico de interações humanas que se pulverizam, não raramente de forma segmentada e dotada de poder mobilizador, na plataforma virtual. "Essa constatação torna imprescindível que as organizações estejam preparadas para atuar neste novo cenário e utilizar os recursos disponíveis de uma forma estratégica." (STASIAK, 2010, p. 35).

Assim, com o objetivo de alavancar a promoção de produtos e marcas e a difusão e venda dos serviços, num mercado competitivo que obedece às dinâmicas e negociações cambiantes em escala local e global, ou com o expresso intuito de comu- 
nicar a adoção de projetos e posicionamentos institucionais, estabelecendo canais de interação que atendam às prioridades inerentes à interdependência organização-públicos, como bem as define o teórico norte-americano James Grunig (2009), o fato é que o ciberespaço se impõe como um território comunicacional de necessária articulação por parte das organizações que, não se mantendo à revelia das tendências e exigências do cenário contemporâneo, seguem cumprindo seus ideais e propósitos.

Chamusca e Carvalhal (2009), pesquisadores brasileiros da área das Relações Públicas, defendem que, ao se situarem no nível estratégico da interatividade na rede, sempre se pautando em conceitos que primam pela ética e pelo fortalecimento da democracia, as Relações Públicas, bem como as demais habilitações vocacionadas à interação das instituições em sociedade, podem contribuir para que as organizações se envolvam de modo mais significativo com as expectativas e anseios comunicacionais dos seus públicos, conquistando a reputação positiva dos seus negócios e uma postura colaborativa por parte daqueles que usufruem dos produtos e serviços ofertados, o público consumidor. Nesse sentido, os autores supracitados salientam que as atividades de comunicação interfaceadas pelas mídias digitais, com foco na divulgação de produtos e vantagens promocionais, assessoria de imprensa, comunicação interna, informações sobre projetos de responsabilidade sociocultural e ambiental e assuntos referentes a direitos, sustentabilidade e cidadania, devem se pautar num processo criterioso, galgados em bases éticas muito bem definidas e pensadas estrategicamente,

[...] visto que, graças à nova arquitetura de participação democrática potencializada, a rede tem o poder de propalar aspectos positivos a respeito da organização, mas também de difundir, em larga escala, uma ação que seja considerada antiética pelos seus usuários, levando a organização a experimentar crises de imagem de grandes proporções. (CHAMUSCA; CARVALHAL, 2009, p. 132).

Nessa linha de entendimento, Pinho (2003) sublinha que o caráter multidimensional das ferramentas de comunicação virtual propicia o garante de uma comunicação aberta, se inserida em políticas de relacionamento bem definidas, de uma instituição com seus diversos públicos de interesse, sobretudo porque esses suportes tecnológicos estruturam um tipo de vínculo social que pode prescindir de referentes correlacionados, diretamente, à noção de tempo e espaço.

A interatividade e a transparência, deste modo, tal como a notoriedade pública das ações organizacionais, revestem-se de novos matizes e sinalizam a indispensabilidade de monitoramento constante das múltiplas e inovadoras formas de sociabilidade, inclusive virtuais, das organizações em seus contextos, locais e globais. Efetivamente, os profissionais da Comunicação devem estar capacitados para esse desafio, operando nesse multiterritório comunicacional, tal como os pesquisadores da área devem empenhar-se para entender essa dinâmica e seus impactos, nitidamente visíveis ou não, na vida social, política, econômica, cultural.

Nesse aspecto, vale pontuar que as expressões metafóricas que ganham corpo e comumente se reproduzem nos cotidianos plurais, na incessante tentativa de nomear o panorama social e tecnológico atual, também no âmbito organizacional, podem ser particularmente úteis no intuito de exemplificar as demandas que irrompem no arcabouço de questionamentos encarados pelas Ciências Humanas e Sociais, como já bem apontara Ortiz (1994), antes mesmo da virada do milênio. "Sociedade da informação", "sociedade do conhecimento", "sociedade informática", "sociedade tecnológica", "sociedade em rede", entre tantas outras, denunciam a emergência de uma paisagem complexa, multiforme, cujas configurações devem ser estudadas e apreendidas, com postura vigilante, pelas Ciências da Comunicação.

\section{Considerações finais}

As sociedades contemporâneas protagonizam constantes processos de reelaboração de suas bases matriciais que conformam pensamentos, hábitos, estilos de vida e exercícios coletivos do poder. Historicamente, a virada do milênio representa o limiar de um tempo que propõe novas dimensões ao campo da economia, política, educação, consumo, artes, entretenimento e cultura, particularmente pela incorporação dos novos aparatos tecnológicos informativo-comunicacionais nas dinâmicas da vida cotidiana de indivíduos e grupos, governos e organizações.

No âmbito da coletividade, regional, nacional ou global, as formas e mecanismos de mobilização 
social e partilha de iniciativas e modos de vida com referenciais comuns contam com os suportes virtuais, desigual e hierarquicamente distribuídos, que, em segundos, interligam localidades, povos e nações, além de estruturar uma esfera pública transfronteiriça de interesses supranacionais, não obstante esforços políticos contraproducentes que, a exemplo do que se tem visto em eventos de visibilidade global sob responsabilidade de governos autoritários, tentam barrar o acesso aberto a informações. No campo da economia e do trabalho, mundializam-se processos produtivos e dinâmicas de reprodução do capital, com o apoio indispensável das tecnologias de informação e comunicação que amparam os fluxos infocomunicacionais diários. Sobretudo, as médias e grandes empresas ampliam seu raio de atuação pela incursão no território virtual, muito embora a amplitude, em certa medida desterritorializada dos negócios, nem sempre, ou dificilmente, assegure a garantia dos direitos e condições dignas de trabalho aos infoproletariados, novos personagens do mundo do trabalho contemporâneo.

Individualmente, na esfera privada das subjetividades, novas possibilidades de configuração do "eu" se colocam no uso da plataforma variável, profusa e multiforme da internet, por meio da qual se renegociam, simbolicamente, identidades pessoais e projetos de imaginação da própria vida. São múltiplos os "eus" que passaram a entranhar e serem estranhados no universo labiríntico do ciberespaço, reclamando condições de experimentar aspirações, desejos e fantasias, a sexualidade, as mais íntimas práticas caladas em outros espaços. O mesmo ciberespaço que conduz às surpresas da descoberta do "eu" pode, paradoxalmente, encaminhar os sujeitos ao confronto ontológico entre o "nós" e o "outro", com certa dose de espanto.

O papel da internet como suporte técnico e simbólico que possibilita distintas formas de sociabilidade, manifestação de identidades e exercícios de democracia, também redimensiona, como vimos nesta proposta reflexiva, os vínculos entre organizações e seus públicos de interação. Esse cenário demanda novos modos de relacionamento entre empresas e os grupos sociais com os quais interagem, ambos ávidos por estruturas comunicacionais que lhes possibilitem, entre um e outro lado, numa via de mão dupla, atingir suas necessidades e anseios.
Nessa perspectiva, a aceitação e legitimidade social de muitas organizações perante seus públicos, como os consumidores, também dependem dos canais e recursos de interatividade virtual que facilitem não apenas a aquisição de produtos e serviços, mas, de igual modo, a solidez dos vínculos desencadeados pelas práticas de consumo. Se bem geridas, essas ferramentas de comunicação podem revelar o esforço institucional em primar pelo respeito e diálogo aberto com o consumidor.

Evidentemente, são as políticas de relacionamento bem definidas que amparam o bom funcionamento da plataforma virtual sob o domínio das organizações, pois, do contrário, sem integrar à filosofia organizacional, diretrizes focadas na gestão de relacionamentos, os recursos de comunicação no ciberespaço e fora dele podem ser usados como verdadeiras armadilhas à própria empresa. Se o mercado, no mundo contemporâneo, se redesenha também pelas possibilidades ofertadas pela internet, é preciso o mergulho vigoroso nesse território tecnológico, mas de forma planejada. A falta de gestão da comunicação virtual por parte das organizações parece-nos mais problemática do que ausência no ciberespaço. É inegável, contudo, que se manter às margens desses processos tecnológicos que desembocam nas esferas econômicas, socioculturais e, portanto, no cotidiano do consumo, pode ser uma realidade cada vez mais distante às organizações modernas.

\section{Referências}

ALVES, G. Reestruturação produtiva e novas tecnologias no século XXI: a quarta idade da máquina e o mundo do trabalho. Disponível em: <http://www.amatra3.com.br/ uploaded_files/NovasTecnologias_palestraAMATRA_ GiovanniĀ-̄ves\%20_1_.pdf>. Acesso: 27 janeiro 2012.

APPADURAI, A. Dimensões culturais da globalização. Lisboa: Teorema, 2004.

BAUMAN, Z. Comunidade: a busca por segurança no mundo atual. Rio de Janeiro: Jorge Zahar Ed., 2003.

CASTELLS, M. A galáxia internet: reflexões sobre a internet, os negócios e a sociedade. Lisboa: Fundação Calouste Gulbenkian, 2002.

A sociedade em rede. Trad. Roneide Venancio Majer, com colaboração de Klauss Brandini Gerhardt. 10.ed. São Paulo: Paz e Terra, 2007. v.1 
CHAMUSCA, M.; CARVALHAL, M. As relações públicas e a formação da opinião pública na Ciber democracia. In: SANTOS, Celia (Org.). Opinião pública: tendências e perspectivas no mundo virtual. Bauru: FAAC-UNESP, 2009.

COSTA, R. A cultura digital. São Paulo: Publifolha, 2003.

DI FELICE, M. Das tecnologias da democracia para as tecnologias da colaboração. In: DI FELICE, M. (Org.). Do público para as redes. São Caetano do Sul: Difusão, 2008. v.1.

FERNANDES, F. A construção do imaginário cyber: William Gibson, criador da cibercultura. São Paulo: Editora Anhembi Morumbi, 2006.

GIBSON, W. Neuromancer. Trad. Alex Antunes. 3. ed. São Paulo: ALEPH, 2003.

GIDDENS, A. A transformação da intimidade: sexualidade, amor e erotismo nas sociedades modernas. Trad. Rosa Maria Perez. Oeiras: Celta, 1995.

Modernidade e identidade. Rio de Janeiro: Jorge Zahar Ed., 2002.

GRUNIG, J. E. Uma teoria geral das relações públicas: quadro teórico para o exercício da profissão. In: GRUNIG, J.; FERRARI, M. A.; FRANÇA, F. Relações públicas: teoria, contexto e relacionamentos. São Paulo: Difusão, 2009.

HARVEY, D. Condição pós-moderna: uma pesquisa sobre as origens da mudança cultural. São Paulo: Edições Loyola, 1992.

HEIM, M. Virtual Realism. New York: Oxford University Press, 1998.

HOBSBAWM, E. J. A era das revoluções: 1789-1848. Trad. Maria Tereza Lopes Teixeira e Marcos Penchel. 25.ed. Rio de Janeiro: Paz e Terra, 2009a.

Da revolução industrial inglesa ao imperialismo. 5. ed. Rio de Janeiro: Forense-Universitária, 2009b.

JENKINS, H. Cultura da convergência. São Paulo: Aleph, 2008.

KUNSCH, M. M. K. Planejamento de relações públicas na comunicação integrada. São Paulo: Summus, 2003.

KUROSE, J. F.; ROSS, K. W. Redes de computadores e a internet: uma nova abordagem. Trad. Arlete Simille Marques; revisão técnica Wagner Luiz Zucchi. São Paulo: Addison Wesley, 2010.

LEMOS, A. Cibercultura: tecnologia e vida social na cultura contemporânea. Porto Alegre: Sulina, 2002.

LEVINE, J. Internet. Rio de Janeiro: Campus, 1998.

LÉVY, P. Cibercultura. 2.ed. São Paulo: Editora 34, 2000.

O que é o virtual. Trad. Paulo Neves. São Paulo:

Editora 34, 2001.
- A inteligência coletiva: por uma antropologia do ciberespaço. 4.ed. São Paulo: Loyola, 2003.

MACHADO, A. Máquina e imaginário: o desafio das poéticas tecnológicas. 2.ed. São Paulo: Edusp, 1996.

MOSCO, V. The digital sublime: myth, power, and cyberspace. Cambridge: MIT Press, 2004.

ORTIZ, R. Mundialização e cultura. São Paulo: Brasiliense, 1994.

. Mundialização, cultura e política. In: DOWBOR, L.; IANNI, O.; RESENDE, P. Desafios da globalização. 4.ed. Rio de Janeiro: Vozes, 2002.

PINHO, J. B. Relações públicas na internet: técnicas e estratégias para informar e influenciar públicos de interesse. São Paulo: Summus, 2003.

RECUERO, R. Redes sociais na internet. Porto Alegre: Sulina, 2009.

RHEINGOLD, H. The virtual comunity. Cambridge: MIT Press, 2000.

RÜDIGER, F. As teorias da cibercultura: perspectivas, questões e autores. Porto Alegre: Sulina, 2011.

SANTAELlA, L. Cultura das mídias. 2.ed. São Paulo: Experimento, 2000.

Cultura e artes do pós-humano: da cultura das mídias à cibercultura. São Paulo: Paulus, 2003.

Navegar no ciberespaço: o perfil cognitivo do leitor imersivo. São Paulo: Paulus, 2004.

STASIAK, D. WebRP: estratégias de relações públicas em portais organizacionais. In: CHAMUSCA, M.; CARVALHAL, M. Relações públicas digitais: o pensamento nacional sobre o processo de relações públicas interfaceado pelas tecnologias digitais. Salvador: Edições VNI, 2010.

TÖNNIES, F. Comunidade e sociedade como entidades típico-ideais. In: FERNANDES, F. (Org.). Comunidade e sociedade: leituras sobre problemas conceituais, metodológicos e de aplicação. São Paulo: Nacional/ Edusp, 1973.

TRIVINHO, E. A dromocracia cibercultural: lógica da vida humana na civilização mediática avançada. São Paulo: Paulus, 2007.

VILCHES, L. A migração digital. Trad. Maria Immacolata Vassallo Lopes. Rio de Janeiro: Editora PUC-Rio, 2003.

Recebido em: 14 de fevereiro de 2013. Aceito em: 03 de junho de 2013. 